Journal of Animal and Veterinary Advances 11 (7): 988-994, 2012

ISSN: $1680-5593$

(C) Medwell Journals, 2012

\title{
Effects of Grain Larvae Extracts on Hepatotoxicity and Blood Lipid in Obese Rats
}

\author{
Park Byung-Sung and Park Sang-Oh \\ Department of Animal Biotechnology, College of Animal Life Science, \\ Kangwon National University, Chuncheon, 200-701 Gangwon-do, Republic of Korea
}

\begin{abstract}
The purpose of this study was to evaluate the effect of the ethanol extract from the grain larvae (GLE: Grain Larvae Ethanol extract) on the blood lipid level of high-fat diet-induced obese rats (Experiment I) and on the protective effect of liver damage in rats that were given intraperitoneal injections of Chlorotetracycline $\left(\mathrm{CCl}_{4}\right)$ and alcohol (Experiment II). For Experiment I, 27 male rats (SDS strain) were randomized into three treatment groups: NC (Normal Control group fed with chow diet without the administration of GLE), HO (High-fat diet induced Obese group) and $\mathrm{HOE}$ (High-fat diet induced Obese rats administered orally with GLE $5.0 \mathrm{mg} / 100 \mathrm{~g}$ body weight). For Experiment II, 45 male rats (SDS strain) were randomized into five treatment groups: T1 (control group), T2 (intraperitoneal injection of $\mathrm{CCl}_{4}$ ), T3 (oral administration of GLE combined with intraperitoneal injection of $\mathrm{CCl}_{4}$ ), T4 (combined administration of GLE and alcohol) and T5 (intraperitoneal injection of alcohol combined with oral administration of GLE). Compared with $\mathrm{HO}$, the levels of triglyceride, total cholesterol and LDL-cholesterol in blood decreased significantly in HOE while the HDL-cholesterol level showed a significant increase $(p<0.05)$. Concentrations of AST, ALT, $\gamma$-GTP and bilirubin in blood significantly decreased in T3 and T5 groups with oral administration of GLE, compared with T2 and T4 groups $(\mathrm{p}<0.05)$. In rats in T3 and T5 groups, recovery of liver tissue cells from damage that had been induced by intraperitoneal injections of $\mathrm{CCl}_{4}(\mathrm{~T} 2)$ and alcohol (T4) could be observed.
\end{abstract}

Key words: Grain larvae, blood lipid, liver protection, obese rats, injection, Korea

\section{INTRODUCTION}

In Korea, high mortality rates of brain and cardiovascular diseases are known to be surpassed only by that of cancer. The potential risk of diseases which are related to the alcoholic fatty liver caused by hyperlipidemia, obesity, diabetes and alcohol abuse is on the rise along with rapid aging of population and increasing trend of meat dietary habit (Seeff et al., 2001). A study on natural bioactive substances that can be used for the prevention of such metabolic syndrome is currently in progress (Eckel et al., 2005).

The high fat diet increases the levels of triglyceride and Low-Density Lipoprotein-Cholesterol (LDL-C) known as harmful cholesterol in blood and decreases the level of high-density lipoprotein-cholesterol known as beneficial cholesterol in blood. A high level of LDL-C in blood has been found to be a major contributor to cardiovascular diseases and can lead to high mortality (Grundy, 1986; Jalali-Khanabadi et al., 2006; Sesal et al., 2009). The liver is an important organ that performs critical functions including nutrients metabolism and detoxication which can decline when it is damaged by hazardous chemical substances and alcohol (Maynard et al., 1972; Ha et al.,
2010). Alcohol abuse can cause overproduction of aldehyde, an alcohol metabolite which may cause alcoholic lever diseases such as various metabolic diseases, hepatitis, liver cirrhosis and liver cancer (Wiilner and Reuben, 2005; Lieber, 1994, 1997). Prolonged alcohol intake and supply of carbon tetracycline $\left(\mathrm{CCl}_{4}\right)$ rapidly increases free radicals from lipid peroxidation in liver tissue causing damage-related liver cytotoxicity resulting in the destruction of liver tissue cell membrane (Noll and Groot, 1984) and the inhibition of protein synthesis, causing the influx of $\gamma$-GTP (GammaGlutamyltranspeptidase), ALT (Alanine Aminotransferase or GPT, glutamic pyruvic transaminase), AST (Aspartate Aminotransferase) or GOT (Glutamic Oxaloacetic Transaminase), $\gamma$-GTP (Gamma-Glutamyltranspeptidase) into the blood stream increasing their levels in blood (Chance et al., 1979; Dakeishi et al., 2004).

Bio-therapy using fly larvae (maggots) was once introduced for the treatment of chronic osteochondritis and purulent infection in the early 20th century and it was later reintroduced following the advent of antibiotics resistant bacteria (Sherman et al., 2000). It has also been reported that the secretion and extract from the maggots were more effective than live maggots themselves

Corresponding Author: Park Sang-Oh, Department of Animal Biotechnology, College of Animal Life Science, Kangwon National University, Chuncheon, 200-701 Gangwon-do, Republic of Korea 
(Jaklic et al., 2008). Jang et al. (2007) reported the existence of MRSA inhibiting peptide of $5 \mathrm{kDA}$ or below in the enzyme digest of hydrosoluble protein obtained from maggots and Jang et al. (2009) reported that ethanol extract has a strong antibacterial effect on MRSA and VRE strain. Park (2007) and Park et al. (2008) found that when different doses of ethanol extract from maggot were orally administered to the rats on chow diet, significantly decreased levels of triglyceride, total cholesterol, LDL-C, atherogenic index and glucose levels were observed in the high dose group and a protective function of liver was reported.

Grain larvae which belong to the house fly family (Muscidae) are a source of natural insect substance and can be grown on grain media such as corns and beans. Grain larvae are known to be free of toxicity and were reported to produce bioactive substances and have a variety of pharmacological potency. It was quoted as having the effects of blood purification and febricide in the Great Chinese Medicine Dictionary, the Chinese medicinal materials encyclopedia and as a remedy for all sensory diseases in Seongchechonglok. According to Bonchogangmok written in the Choseon period, it is prescribed as a febricide when no other febricides were effective. Bonchopyeondok says it is prescribed for the treatment of severe furunculus. However, there has been no study on the effects of the bioactivity of grain larvae.

In this study, GLE (Grain Larvae Ethanol extract) the ethanol extract from grain larvae which had been artificially grown under standard growing condition was used to evaluate its bioactivity effect on lipid metabolism in high fat diet-induced obese rats (Experiment I) and the protective effect on liver damage in rats which were given intraperitoneal injections of $\mathrm{CCl}_{4}$ and alcohol (Experiment II).

\section{MATERIALS AND METHODS}

The samples of blow-dried grain larvae supplied by Golden King Bio were compressed at $1,000 \mathrm{psi}, 150^{\circ} \mathrm{C}$ for $30 \mathrm{~min}$. After such compression, the residue as primarily defatted was processed with hexane to obtain the grain larvae as completely defatted. The mixture of the defatted residue of the grain larvae with the pure ethanol was then prepared at the ratio of $1: 10$ and subjected to three consecutive $3 \mathrm{~h}$ extraction processes at $60^{\circ} \mathrm{C}$ using a Reflux Condensing System to obtain ethanol extracts. These ethanol extracts were then depressurized and concentrated at $40^{\circ} \mathrm{C}$ in water using a rotary vacuum concentrator (Eyela N-1000, Tpkyo Rikakikai Co., Japan) and stored in a freezer for use as samples. Using the above method, $3.5 \%$ ethanol extracts could be obtained.
Animal experiments had been approved by the Institutional Animal Care and Use Committee (IACUC) of Kangwon National University and were conducted ethically and scientifically according to the procedures recommended in the EEC guideline for the licensing for the care and use of lab animals. Doses of GLE to be orally administered to the animals in the Experiment I and II were determined at the level where the plateau of an decreasing effect of lipid in blood would appear from several precedent studies based on the experimental results by Park (2007).

For Experiment I, 27 male rats (SDS) having an average weight of $200 \mathrm{~g}$ which were purchased from Daihan Bio Link, Korea were used for the 4 weeks experiment following their adaptation to the breeding environment in the laboratory for 1 week. These rats were randomized into three treatment groups by three repeats (3 rats/repeat). These groups were: NC (Normal Control group fed with chow diet without the administration of GLE), $\mathrm{HO}$ (High-fat diet induced Obese group) and $\mathrm{HOE}$ (High-fat diet induced Obese rats administered orally with GLE $5.0 \mathrm{mg} / 100 \mathrm{~g}$ body weight). Animal feeds for such experiments were prepared by palletizing purified diets as prepared on the basis of AIN (1977). Purified diet was prepared so that they might contain an equal amount of energy content and protein content, composed of casein $20.0 \%$, corn starch $15.0 \%$, sugar $50.0 \%$, $\gamma$-cellulose $5.0 \%$, corn oil $5.0 \%$, minerals $3.5 \%$, vitamins $1.0 \%$, choline bitrate $0.2 \%$ and DL-methionine $0.3 \%$. Composition of the high-fat diet was determined by adjusting composition of the chow diet by replacing $20 \%$ of sugar with lard $20 \%$ so that there was $20 \%$ of lipid content in the high-fat diet consisting of corn oil 5\% and lard 20\%.

For Experiment II, 45 male rats (SDS) having an average weight of $200 \mathrm{~g}$ which were purchased from Daihan Bio Link were used for the 20 days experiment following their adaptation to the breeding environment at the laboratory for 1 week. These rats were randomized into five treatment groups by three repeats ( 3 rats per repeat). These groups were: T1 (Control group), T2 (intraperitoneal injection of $\mathrm{CCl}_{4} 0.5 \mathrm{~mL} / 100 \mathrm{~g}$ of body weight once on day 1), T3 (oral administration of GLE $5.0 \mathrm{mg} / 100 \mathrm{~g}$ of body weight daily for 19 days followed by intraperitoneal injection of $\mathrm{CCl}_{4} 0.5 \mathrm{~mL} / 100 \mathrm{~g}$ of body weight once on day 20), T4 (Oral administration of GLE $5.0 \mathrm{mg} / 100 \mathrm{~g}$ of body weight daily for 20 days combined with intraperitoneal injection of $20 \%$ alcohol of $0.514 \mathrm{~mL}$ on days 6, 12 and 18) and T5 (Intraperitoneal injection of $20 \%$ alcohol of $0.514 \mathrm{~mL} / 100 \mathrm{~g}$ of body weight daily for 19 days followed by oral administration of GLE $5.0 \mathrm{mg} / 100 \mathrm{~g}$ of body weight once on day 20). The 
breeding environment condition at the laboratory was maintained at the temperature of $20 \pm 2^{\circ} \mathrm{C}$ and the relative humidity of $60 \pm 5 \%$ and illumination was adjusted at an interval of $12 \mathrm{~h}$. Experimental diets and water were supplied without limit and daily average of weight gains, dietary intake and dietary efficiency were measured during the experiment period.

Sacrifice of experimental animals was conducted $12 \mathrm{~h}$ after discontinuation of the supply of diet except water for the convenience of anesthesia and zootomy. In order to prevent blood coagulation, blood was injected through the heparinized vacuum tube (Becton Dickinson Vacutainer System, Franklin lakes, NJ 07417, USA) into the abdominal aorta using a heparinized syringe after anesthetizing the rat with a light injection of ethyl ether. Plasma was separated from the rat blood by centrifugation at 3,000 rpm for $20 \mathrm{~min}$ and the separated plasma was then quick-frozen using liquid nitrogen $\left(-196^{\circ} \mathrm{C}\right)$ and stored with it being frozen at $-20^{\circ} \mathrm{C}$ until next biochemical analysis. Liver, kidney, heart, spleen, thymus and abdominal fat were removed immediately after blood collection and weighed after washing with physiological saline and draining moisture by adsorbing each of them through the Whatman filter paper (No. 2).

Contents of triglyceride, total cholesterol and HDL-C in the lipid fraction in blood were quantified using Enzyme kit for the commercial use (Asan Pharm., Korea) and a content of LDL-C was calculated using Friedwald Equation (1972). Atherogenic Index (AI) for evaluation of the cardiovascular disease risk was calculated according to the applicable equation of [(total cholesterol)-(HDLC) $/ \mathrm{HDL}-\mathrm{C}$ (Yuji, 2005). Contents of bilirubin and $\gamma$-GTP in blood were measured using the Orlowski's method and contents of AST and ALT were measured using Enzyme kit for the commercial use (Yungdong Pharm., Korea) by applying Karmen's Method.

In order to evaluate the degree of histological damage of hepatocytes, rats were sacrificed and tissue was collected from the middle lobe immediately after the abdominal section was fixated in $4 \%$ formaldehyde solution. This tissue was subjected to a dewatering process and cut to $4 \sim 5 \mu \mathrm{m}$ of tissue slices using paraffin and then dyed with Hematoxylin-Eosin (H-E) stain. Such dyed tissue slices were observed at x200 magnification using an optical microscope (Olympus AX79, Japan) for comparison and interpretation of liver damage status resulted from administration of GLE.

Statistical analysis: SAS program was used for statistical processing of the analyzed data. After calculating the median and standard deviations and performing the distribution analysis, statistical significance was tested at 95\% confidence interval $(\mathrm{p}<0.05)$ using the Duncan's multiple range test (SAS, 2004).

\section{RESULTS AND DISCUSSION}

Experiment I: Dietary intake, body weight gain and diet efficiency of high-fat diet-induced obese rats after oral administration of GLE are shown in Table 1. A daily average dietary intake decreased in the obese rat group and the GLE-administered rat group, compared with the control group. And compared with the obese rat group, GLE-administered rats had a significant increase in dietary intake showing a trend of improvement after administration of GLE. A daily average gain of body weight increased significantly in the obese rat group and the GLE-administered group compared with the control group. And compared with the obese rat group, body weights of the GLE-administered rats decreased significantly showing an obesity control effect of GLEadministration. Diet efficiency was higher in the obese rat group and the GLE-administered rat group, compared with the control group which had statistical significance. Rats in the obese group in particular showed the lowest dietary demand necessary for weight gain. The fact that the body weight gain and the diet efficiency were high in the obese rat group even though these rats had less dietary intake, confirms the results reported by Park et al. (2008). It may be explained that because intake of high-fat diet during the experiment period supplied high energy, despite the relatively low dietary intake, the accumulated body fat contributed to the weight gain more than the increased muscle mass (Table 2). Since, the animal dietary intake is

Table 1: Growth performances in rats fed the experimental diets for 4 weeks (g/day/head)

\begin{tabular}{llcc}
\hline Groups $^{1}$ & Diet intake & Weight gain & FER $^{2}$ \\
\hline NC & $20.73 \pm 0.28^{3 \mathrm{a}}$ & $5.85 \pm 0.12^{\mathrm{c}}$ & $0.28 \pm 0.01^{\mathrm{c}}$ \\
HO & $18.29 \pm 0.33^{\mathrm{c}}$ & $7.14 \pm 0.37^{\mathrm{a}}$ & $0.39 \pm 0.02^{\mathrm{a}}$ \\
HOE & $19.68 \pm 0.27^{\mathrm{b}}$ & $6.43 \pm 0.21^{\mathrm{b}}$ & $0.33 \pm 0.01^{\mathrm{b}}$ \\
\hline
\end{tabular}

${ }^{1} \mathrm{NC}$ : Normal Control, HO: High-fat diet induced Obese rats, HOE: High-fat diet induced obese rats with $5.0 \mathrm{mg}$ extracts $100 \mathrm{~g}^{-1}$ BW. ${ }^{2} \mathrm{FER}$ : Food Efficiency Ratio (weight gain/diet intake), ${ }^{3}$ Values are mean \pm standard errors $\left(\mathrm{n}=9\right.$ ). ${ }^{\mathrm{a}-\mathrm{c}}$ Values with different superscripts within the same column are significantly different at $\mathrm{p}<0.05$

Table 2: Organ weight in rats fed the experimental diets for 4 weeks ( $\mathrm{g} / 100 \mathrm{~g}$ body weight)

\begin{tabular}{lllllc}
\hline Groups $^{1}$ & Liver & Kidney & Heart & Spleen & Adipose tissue \\
\hline NC & $3.09 \pm 0.41^{2 b}$ & $0.69 \pm 0.35$ & $0.37 \pm 0.10$ & $0.30 \pm 0.18$ & $3.87 \pm 0.25^{c}$ \\
HO & $4.35 \pm 0.19^{\mathrm{a}}$ & $0.61 \pm 0.29$ & $0.33 \pm 0.06$ & $0.29 \pm 0.01$ & $6.72 \pm 0.27^{\mathrm{a}}$ \\
HOE & $3.11 \pm 0.15^{\mathrm{b}}$ & $0.62 \pm 0.07$ & $0.32 \pm 0.15$ & $0.31 \pm 0.05$ & $5.01 \pm 0.16^{b}$ \\
\hline
\end{tabular}

${ }^{1}$ The same as Table $1 .{ }^{2}$ Values are mean \pm standard errors $(n=9)$. ${ }^{\text {acc }}$ Values with different; uperscripts within the same column are significantly different at $\mathrm{p}<0.05$ 
determined by the energy demand, it is known that dietary intake decreases when the animal is fed with high-energy diet rather than low-energy diet (Van Zutphen et al., 1993). Changes in weights of liver, kidney, heart, spleen and the fat tissue in high-fat diet-induced obese rats after administration of GLE are as shown in Table 2. Liver weight increased significantly in the obese rat group, compared with the control group but no significant difference could be observed between the control group and the obese rat group. The fat tissue weight was significantly higher in the obese rat group and the GLE-administered group, compared with the control group and it decreased significantly in the GLE-administered group, compared with the obese rat group, proving an effect of GLE on reducing body fat accumulation. The experiment results showed similar trends to the results of the study performed by Park et al. (2008) showing that weights of liver and fat tissue increased in the high-fat diet-induced obese rat group, compared with rats of the chow diet intake group. Since, intake of the high-fat diet generally causes lipid metabolism disorders in liver resulting in fat accumulation in the liver tissue, the liver weight increases more with the high-fat diet than with the chow diet (Leo et al., 1983).

Changes of blood lipids in high-fat diet-induced obese rats after administration of GLE are shown in Table 3 . The triglyceride level increased significantly in the obese rat group than in the control group but no significant difference could be observed between the control group and the GLE administered group. The total cholesterol level, the LDL-C level and the atherogenic index were significantly higher in the obese rat group and the GLE-administered group than in the control group which showed a significant decrease in the GLEadministered group compared with the obese rat group,

Table 3: Plasma lipid profile in rats fed the experimental diets for 4 weeks (mg dL ${ }^{-1}$ )

\begin{tabular}{|c|c|c|c|}
\hline \multirow[b]{2}{*}{ Items $^{2}$} & \multicolumn{3}{|l|}{ Groups $^{1}$} \\
\hline & $\mathrm{NC}$ & $\mathrm{HO}$ & $\mathrm{HOE}$ \\
\hline Triacylglyceride & $97.31 \pm 5.74^{3 b}$ & $140.50 \pm 8.45^{\mathrm{a}}$ & $107.80 \pm 8.17^{\mathrm{b}}$ \\
\hline Total cholesterol & $75.63 \pm 8.24^{c}$ & $115.80 \pm 5.78^{\mathrm{a}}$ & $93.40 \pm 5.47^{b}$ \\
\hline $\mathrm{HDL}-\mathrm{C}$ & $45.72 \pm 2.07^{\mathrm{a}}$ & $31.70 \pm 3.15^{c}$ & $40.85 \pm 2.55^{b}$ \\
\hline LDL-C & $10.45 \pm 5.08^{c}$ & $56.00 \pm 8.16^{\mathrm{a}}$ & $30.99 \pm 5.43^{b}$ \\
\hline $\mathrm{AI}$ & $0.65 \pm 0.10^{c}$ & $2.66 \pm 0.15^{a}$ & $1.29 \pm 0.12^{\mathrm{b}}$ \\
\hline
\end{tabular}

${ }^{1}$ The same as Table $1 .{ }^{2} \mathrm{HDL}-\mathrm{C}$ : High Density Lipoprotein, LDL-C: Low Density Lipoprotein-Cholesterol, AI: Atherogenic Index (TC-HDLC)/HDL-C. ${ }^{3}$ Values are mean \pm standard errors $(n=9)$. ${ }^{a-c}$ Values with different superscripts within the same row are significantly different at $p<0.05$ proving an effect of GLE administration on lowering the lipid level in blood. The HDL-C content was highest in the control group followed by the GLE administered group and then the obese rat group with statistically significant differences among the treatment groups. An important finding in this experiment was that oral administration of GLE could lower the lipid level in blood in the high-fat diet-induced obese rats. The experiment results showed similar trends to the results of the study performed by Park et al. (2008) showing that the lipid level in blood significantly increased in the high-fat diet-induced obese rat group compared with the rats of the chow diet intake group. Also the results ofthe study performed by Park (2007) that the ethanol extract of fly larvae had an effect of significantly lowering the lipid level in blood support the results of the study. It is a common knowledge that high contents of triglyceride and LDL-C in blood cause increased mortality due to cardiovascular diseases such as myocardial infarction and arteriosclerosis and a high content of HLD-C helps prevent them (Jensen et al., 1999). LDL, the lipid transporter playing the most crucial role in cholesterol accumulation in the artery, transports cholesterol ester from liver to blood and peripheral tissue cells in many parts of the body while HDL is a lipid protein transporting cholesterol from artery to liver. Since, an increase of the level of HDL-C in blood enhances transport of cholesterol from blood and body tissues to liver such reverse transport of cholesterol in effect removes cholesterol from blood. Therefore, since a high level of LDL-C in blood is harmful to health, LDL-C is dubbed as a bad cholesterol while HDL-C is dubbed as a good cholesterol (Grundy, 1986). An atherogenic index represents a content of triglyceride relative to $\mathrm{HDL}-\mathrm{C}$ in the body and a high risk of arteriosclerosis is considered when it is $>3.0$ (Rosenfeld, 1989). Another new finding in the experiment was observation of decreased lipids in blood in the GLE-administered group which suggests that GLE may also have a bioactive effect on improving lipid metabolism in a human.

Experimental II: The results of evaluating an effect of GLE administration on levels of liver-related enzymes in blood in rats which were fed on the chow diet and given intraperitoneal injections of $\mathrm{CCl}_{4}$ and alcohol equivalent to one bottle of Soju (Korean distilled liquor) in an adult human are as shown in Table 4 . Compared with $\mathrm{T} 1$ as the

Table 4: Levels of $\gamma$-GTP, AST, ALT and Bilirubin of plasma after orally administered of grain larvae extracts in rats ${ }^{1}$

\begin{tabular}{|c|c|c|c|c|c|}
\hline Items & $\mathrm{T} 1$ & $\mathrm{~T} 2$ & T3 & $\mathrm{T} 4$ & T5 \\
\hline$\gamma$-GTP $\left(m U \mathrm{~mL}^{-1}\right)$ & $7.65 \pm 3.74^{2 e}$ & $50.53 \pm 3.55^{\mathrm{a}}$ & $29.44 \pm 2.97^{b}$ & $13.59 \pm 2.87^{\mathrm{d}}$ & $20.18 \pm 3.14^{c}$ \\
\hline AST (karmen $\mathrm{mL}^{-1}$ ) & $160.3 \pm 9.010^{c}$ & $t^{3}$ & + & $185.1 \pm 9.560^{\mathrm{a}}$ & $178.7 \pm 9.470^{b}$ \\
\hline ALT (karmen $\mathrm{mL}^{-1}$ ) & $48.53 \pm 3.15^{b}$ & + & + & $45.13 \pm 3.77^{c}$ & $63.23 \pm 4.01^{\mathrm{a}}$ \\
\hline Bilirubin $\left(\mathrm{mg} \mathrm{dL}^{-1}\right)$ & $0.34 \pm 0.71^{\mathrm{d}}$ & $1.35 \pm 0.83^{\mathrm{a}}$ & $0.67 \pm 0.52^{b}$ & $0.33 \pm 0.20^{d}$ & $0.48 \pm 0.32^{c}$ \\
\hline
\end{tabular}

${ }^{1} \mathrm{~T} 1$ : Control, $\mathrm{T} 2$ : Intraperitoneal injection of $\mathrm{CCl}_{4}, \mathrm{~T} 3$ : Intraperitoneal injection of $\mathrm{CCl}_{4}$ after orally administered with GLE, T4: Orally administered with combination of GLE and alcohol, T5: Orally administration of GLE after orally administered with alcohol. ${ }^{2}$ Values are mean \pm standard errors $\left(\mathrm{n}=9\right.$ ). ${ }^{3}+:$ Above 200 karmen unit $\mathrm{mL}^{-1}$. $^{\mathrm{a}-\mathrm{e}}$ Mean values with different superscripts are significantly different at $\mathrm{p}<0.05$ 
Table 5: Changes in organ weight after orally administered of grain larvae extracts in rats ${ }^{1}(\mathrm{~g} / 100 \mathrm{~g}$ body weight)

\begin{tabular}{lccccc}
\hline Items & T1 & T2 & T3 & T4 & T5 \\
Liver & $3.51 \pm 0.31^{2 b}$ & $4.43 \pm 0.11^{\mathrm{a}}$ & $4.27 \pm 0.24^{\mathrm{a}}$ & $3.74 \pm 0.14^{\mathrm{b}}$ & $4.50 \pm 0.25^{\mathrm{a}}$ \\
Spleen & $0.30 \pm 0.08^{\mathrm{a}}$ & $0.14 \pm 0.07^{\mathrm{b}}$ & $0.16 \pm 0.11^{\mathrm{b}}$ & $0.27 \pm 0.17^{\mathrm{a}}$ & $0.19 \pm 0.09^{\mathrm{b}}$ \\
Thymus & $0.15 \pm 0.13^{\mathrm{a}}$ & $0.04 \pm 0.01^{\mathrm{c}}$ & $0.09 \pm 0.02^{\mathrm{b}}$ & $0.14 \pm 0.02^{\mathrm{a}}$ & $0.09 \pm 0.01^{\mathrm{b}}$ \\
Abdominal fat & $0.57 \pm 0.05^{\mathrm{c}}$ & $0.97 \pm 0.03^{\mathrm{b}}$ & $0.83 \pm 0.05^{\mathrm{b}}$ & $0.60 \pm 0.02^{\mathrm{c}}$ & $1.29 \pm 0.13^{\mathrm{a}}$ \\
\hline
\end{tabular}

${ }^{1}$ The same as Table $3 .{ }^{3}$ Values are mean \pm standard errors $(n=9) .{ }^{a-c}$ Mean values with different superscripts are significantly different at $p<0.05$

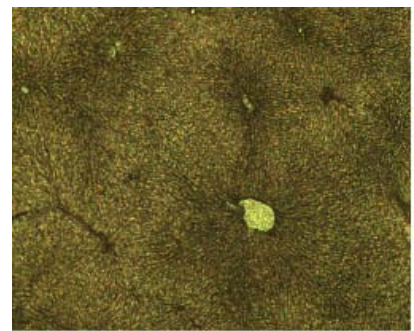

T1

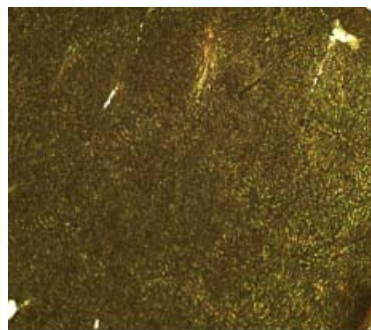

$\mathrm{T} 2$

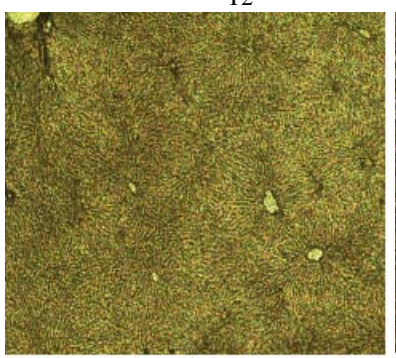

T4

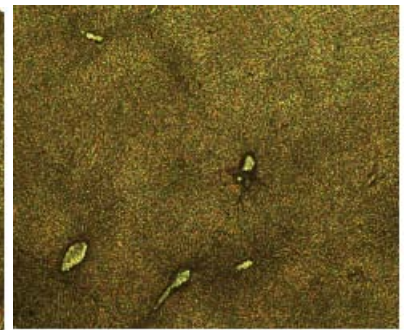

T3

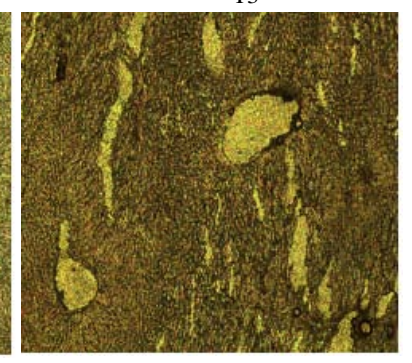

$\mathrm{T} 5$

Fig. 1: The light microscopic features of liver in rats ( $\mathrm{H}$ and $\mathrm{E}, \mathrm{x} 200$ ); $\mathrm{T} 1$ (control), $\mathrm{T} 2$ (intraperitoneal injection of $\mathrm{CCl}_{4}$, T3 (intraperitoneal injection of $\mathrm{CCl}_{4}$ after orally administered with GLE, T4 (orally administered with combination of GLE and alcohol and T5 (orally administration of GLE after orally administered with alcohol)

control group, the $\gamma$-GTP level was highest in T2 as the intraperitoneal $\mathrm{CCl}_{4}$ injection group followed by $\mathrm{T} 3$, T5 and $\mathrm{T} 4$ in the order namedwhile significant differences were among the treatment groups. Compared with $\mathrm{T} 1$, the AST level was higher in T2, T3, T4 and T5 in the order named and the ALT level was higher in T2, T3, T5 and T1 in the order named than in $\mathrm{T} 1$ while the lowest level was found in T4 and no statistically significant differences were among the treatment groups. Compared with $\mathrm{T} 1$, bilirubin level was higher in T2, T3, T4 and T5 in the order named while statistically significant differences were among the treatment groups. Such results had a significant effect in the GLE administered group on maintaining a stable weight of organs (Table 5) and preventing a hepatocyte damage (Fig. 1) which may be attributable to the action of bioactive peptide contained in GLE (Jang et al., 2007). AST and ALT, amino acid synthesizing enzymes existing in liver and other organs are used in evaluation of the hepatocyte damage and $\gamma$-GTP and bilirubin are used in evaluation of the hepatocyte damage and the flow of bile. These enzymes are widely known as indicators of suspected hepatitis, fatty liver, alcoholic liver disorder, hepatic cirrhosis and biliary obstruction by their increased levels. Levels of these enzymes decreased significantly in the rats in $\mathrm{T} 4$ which had a combined administration of alcohol and GLE compared with the rats in T5 which had a long-tern alcohol intake. It was notable that the ALT level decreased in $\mathrm{T} 4$ to a lower level than in the control group, T1. A new finding from this experiment was that administration of GLE could reduce levels of the above enzymes which were normally increased due to liver damage.

The results of evaluating the effect of GLE administration on organ weights in rats which were fed on the chow diet and given intraperitoneal injections of $\mathrm{CCl}_{4}$ and alcohol equivalent to one bottle of Soju in the human adult are as shown in Table 5. Compared with $\mathrm{T} 1$ as the control group, the liver weight increased significantly in $\mathrm{T} 2$, T3 and T5 indicating hepatomegaly but no significant difference could be observed between $\mathrm{T} 1$ and $\mathrm{T} 4$. Compared with $\mathrm{T} 1$, weights of spleen and thymus decreased significantly in $\mathrm{T} 2, \mathrm{~T} 3$ and $\mathrm{T} 5$ but no statistically significant difference could be observed between $\mathrm{T} 1$ and $\mathrm{T} 4$.

No significant difference of the weight of the celiac fat was observed between $\mathrm{T} 1$ and $\mathrm{T} 4$ which were given daily oral administration of GLE of $5.0 \mathrm{mg} / 100 \mathrm{~g}$ of body weight for 20 days and intraperitoneal injection of $20 \%$ alcohol of $0.514 \mathrm{~mL}$ on day 6,12 and 18 th but compared 
with $\mathrm{T} 1$, $\mathrm{T} 5$, they showed higher accumulation rates followed by $\mathrm{T} 2$ and $\mathrm{T} 3$ in the order named while there were statistically significant differences among groups. The fact that the liver weight showed significantly a higher level of hepatomegaly in rats in T2, T3 and T5 which were given intraperitoneal injections of $\mathrm{CCl}_{4}$ or alcohol compared with $\mathrm{T} 1$ as the control group and T4 as the group which was given combined adminstration of alcohol and GLE may be attributable to the liver damage that caused a disorder in metabolism of nutrients and other substances resulting in accumulation of the excessive amount of such substances in the liver tissue. Excessive intake of alcohol through alcohol abuse may cause fatty liver and fibrosis of the liver tissue cells leading to hepatomegaly (Leo et al., 1983). A new finding was made from the results of this experiment that administration of GLE can prevent alcoholic hepatomegaly of liver tissue cells, reduce abdominal fat and activate immune organ cells.

The results of evaluating the effect of GLE administration on morphologic changes in liver tissue cells in rats which were fed on the chow diet and given intraperitoneal injections of $\mathrm{CCl}_{4}$ and alcohol equivalent to one bottle of Soju in the human adult are as shown in Fig. 1. The classic hepatic lobules of liver tissue cells in normal rats (T1) show parallel arrangement of radial hepatic cell cords and sinusoids from the central vein. In $\mathrm{T} 2$ rats which were given a $\mathrm{CCl}_{4}$ injection, damaged endothelial cells in the liver tissue were observed and parts of hepatocytes were swollen in the periphery of the central vein, causing severe disruption of hepatocytes arrangement which normally should have radial arrangement toward the periphery of the classic hepatic lobules. However, it was observed that such damage degree in hepatocytes was less pronounced in rats in T3 which were given GLE administration followed by an intraperitoneal injection of $\mathrm{CCl}_{4}$. The hepatocytes in rats in T4 which were given administration of alcohol and GLE in combination, showed some damage in a higher degree than those in normal hepatocytes in $\mathrm{T} 1$ but in a less degree than in $\mathrm{T} 3$. In the rats in $\mathrm{T} 5$ which were given a long-term administration of alcohol followed by administration of GLE not only the hepatic central vein but also the radial arrangement was almost damaged, showing the most severe damage among the treatment groups. It was found that such damage of hepatocyte caused an increase in levels of enzymes in blood which entered the blood stream (Table 4). A new finding from these experimental results was that administration of GLE can very effectively help prevent oxidation and alcohol-related liver tissue damage. The result of observing morphologically the liver tissue in rats which were given the administration of $\mathrm{CCl}_{4}$ (T2) in this experiment was similar to the result of observing severe tissue necrosis in the periphery of the central vein and hepatocyte damage accompanied by changes in fatty acid around the necrosed tissue as reported by Kim et al. (2007).

\section{CONCLUSION}

In this study, researchers believe that grain larvae extracts can help improve the obesity-related lipid metabolism in blood and prevent an alcoholic liver damage for prevention of human diseases in the medical and life science era.

\section{ACKNOWLEDGEMENT}

This study was supported by Korea Institute of Planning and Evaluation for Technology in Food, Agriculture, Forestry and Fisheries (Project No: C1006638-01-02), 2009.

\section{REFERENCES}

AIN, 1977. Report of the American institute of nutrition ad hoc committee on standards for nutritional studies. J. Nutr., 107: 1340-1348.

Chance, B., H. Sies and A. Boveris, 1979. Hydroperoxide metabolism in mammalian organs. Physiol. Rev., 59: 527-605.

Dakeishi, M., T. Iwate, N. Ishil and K. Murata, 2004. Effect of alcohol consumption on hepatocellular injury in Japanese man. Tohoku J. Exp. Med., 202: 31-39.

Eckel, R.H., S.M. Grundy and P.Z. Zimmet, 2005. The metabolic syndrome. Lancet, 365: 1415-1428.

Grundy, S.M., 1986. Cholesterol and coronary heart disease: A new era. J. Am. Med. Assoc., 256: 2849-2858.

Ha, Y.L., Y.S. Kim, C.R. Ahn, J.M. Kweon, C.W. Park, Y.K. Ha and J.O. Kim, 2010. Mycelial culture of lentinusedodes alleviates rat liver toxicity induced by carbon tetrachloride and ethanol. J. Life Sci., 20: 133-141.

Jaklic, D., A. Lapanje, K. Zupancic, D. Smrke and N. Gunde-Cimerman, 2008. Selective antimicrobial activity of maggots against pathogenic bacteria. J. Med. Microbiol., 57: 617-625.

Jalali-Khanabadi, B.A., H. Mozaffari-khosravi, M. Rafiei, S.M. Ghoreishian and F. Darabi, 2006. Association of cholesterol-rich lipoproteins with coronary artery disease in subjects who referred to yazd cardiovascular research center for coronary angiography. Pak. J. Biol. Sci., 9: 2777-2780. 
Jang, A., C.R. Cho, B.S. Park and K.J. Yoon, 2007. Seperation of antibaterial low molecular peptides from Muscadomesica maggot against MethicillinResistant Staphylococcus aureus (MRSA) and Vancomycin Resistant Enterococcus (VRE). Proceedings of the International Symposium and Annual Meeting, October 17-19, 2007, Social Food Science Nutration, Korean.

Jang, A., S.O. Park, J.H. Shin, W.K. Choi and B.S. Park, 2009. Antibacterial activity of ethanol extracts from house fly-maggot against various strains of methicillin-resistant Staphylococcus aureus and vancomycin-resistant enterococci strain. Ann. Anim. Resour. Sci., 20: 6-15.

Jensen, J., A. Bysted, S. Dawids, K. Hermansen and G. Holmer, 1999. The effect of palm oil, lard and puffpastry margarine on postprandial lipid and hormone responses in normal-weight and obese young women. Br. J. Nutr., 82: 469-479.

Kim, D.H., Y.K. Deung, Y.M. Lee, Y.S. Yoon andK.J. Lee, 2007. The effect of saengshik on the hepatotoxicity of mouse induced by carbon tetrachloride. Korean J. Electron. Microsc., 37: 11-21.

Leo, M.A., M. Sato and C.S. Lieber, 1983. Effect of hepatic vitamin A depletion on the liver in human and rats. Gastroenterol., 84: 562-572.

Lieber, C.S., 1994. Alcohol and liver. Gasroeenterol, 106: $1085-1090$.

Lieber, C.S., 1997. Ethanol metabolism, cirrhosis and alcoholism. Clin. Chim. Acta, 257: 59-84.

Maynard, E.H., S. Brittern and R.G. James, 1972. 1972Effect of 3-methylchloanthrene induction on the CCL4-induced changes in rat hepatic microsomal enzyme system. Biochem. Pharmacol., 21: 745-747.
Noll, T. and H.D. Groot, 1984. The critical steady-state hypoxic conditions in carbon tetrachloride-induced lipid peroxidation in rat liver microsome. Biochem. Biophys. Acta, 795: 356-362.

Park, B.S., 2007. A study on the bioactive effect of ethanol extracts from fly larvae. J. Environ. Agric. Res., 9: 9-22.

Park, C.H., D.I. Kim, H.K. Jung, G.D. Lee, K.S. Kim and J.H. Hong, 2008. of Bulnesia sarmienti single and complex extracts on serum lipid and body fat in rats fed high-fat diet. Korean J. Food Sci. Technol., 40: 449-454.

Rosenfeld, L., 1989. Lipoprotein analysis. Arch. Pathol. Lab. Med., 113: 1101-1110.

SAS, 2004. SAS/STAT: Guide to Personal Computers. SAS Institute Inc., Cary, North Carolina.

Seeff, L.B., K.L. Lindsay, B.R. Bacon, T.F. Kresina and J.H. Hoofnaqle, 2001. Complementary and alternative medicine in chronic liver disease. Hepatology, 34: 595-603.

Sesal, C., F. Ciloglu, I. Peker and N. Sayar, 2009. Role of angiotensin converting enzyme, paraoxonase 155 , 192 gene polymorphisms in syndrome $\mathrm{X}$ and coronary heart disease. Pak. J. Biol. Sci., 12: 46-51.

Sherman, R.A., M.J. Hall and S. Thomas, 2000. Medicinal maggots: An ancient remedy for some contemporary afflictions. Annu. Rev. Entomol., 45: 55-81.

Van Zutphen, L.F.M., V. Baumans and A.C. Beynen, 1993. Principles of Laboratory Animal Science. Elsevier, Netherlands. pp: 109-113.

Wiilner, I.R. and A. Reuben, 2005. Alcohol and the liver. Curr. Opin. Gastroenterol., 21: 323-330.

Yuji, T., 2005. Serum lipid levels and factors affecting atherogenic index in Japanese children. J. Physiol. Anthropol. Appl. Human Sci., 24: 511-515. 